\title{
Queen Bees and Domestic Violence: Patrilocal Marriage in Tajikistan
}

\author{
Charles Becker Mavzuna R. \\ Turaeva \\ Duke University Duke University
}

October 31, 2016

ERID Working Paper Number 232

This paper can be downloaded without charge from the Social Science Research Network Electronic Paper Collection:

http://ssrn.com/abstract=2862096

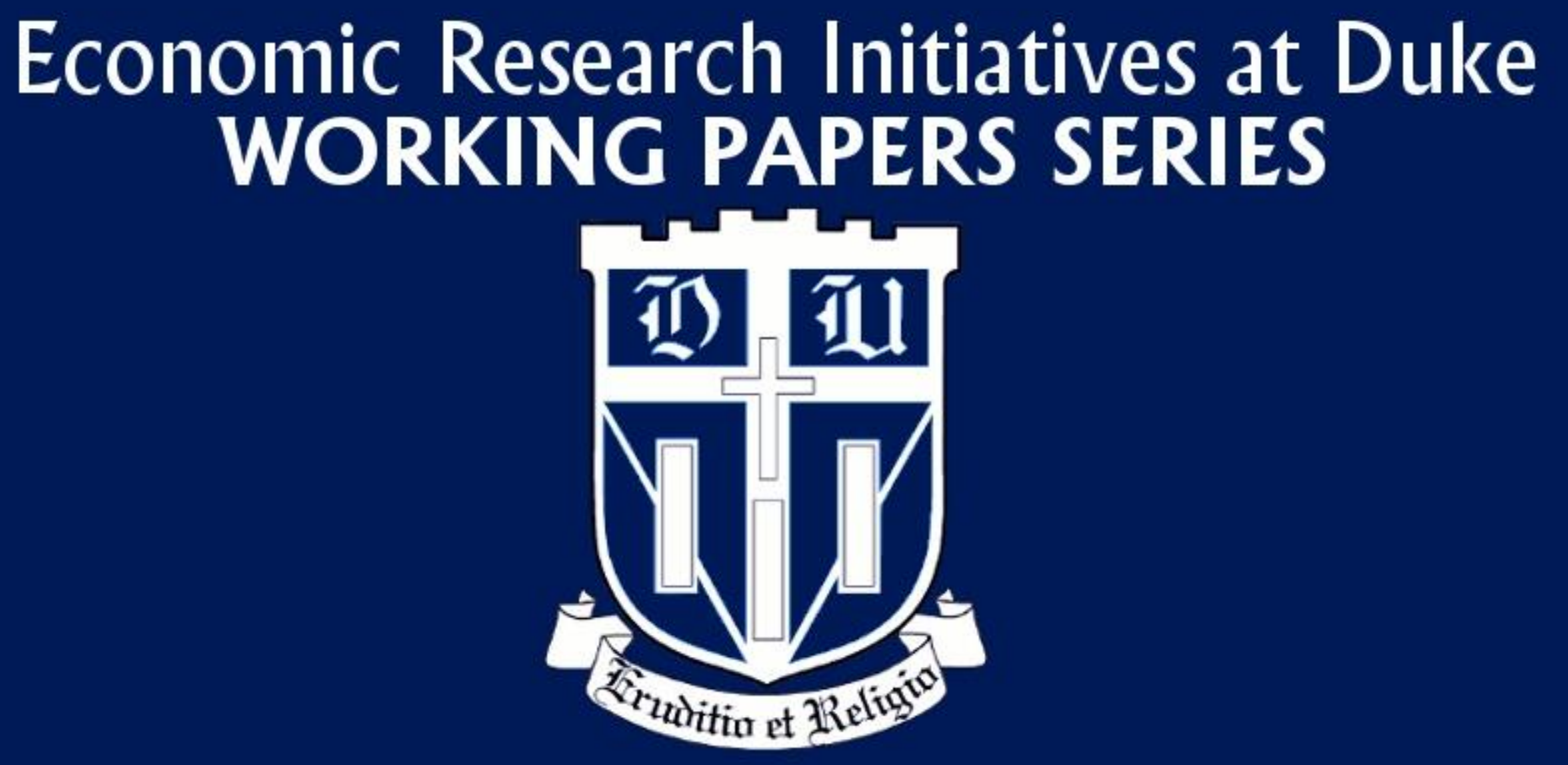




\title{
QUEEN BEES AND DOMESTIC VIOLENCE: PATRILOCAL MARRIAGE IN TAJIKISTAN
}

\author{
Mavzuna R. Turaeva and Charles M. Becker \\ Department of Economics \\ Duke University
}

October 2016

\begin{abstract}
:
A longstanding tradition of patrilocal marriage - living with the parents-in-law - affects every generation of Central Asian women and their choices regarding childbearing, employment and education. While anthropological evidence suggests that elder matriarchs (Queen Bees) play a key and often detrimental role in the lives of the junior women in their households, rigorous empirical studies are scarce. We use Tajikistan 2012 DHS data to explore the correlation between domestic violence and young married women's living arrangements. Through a quasi-experimental study designed, we establish a positive and statistically significant treatment effect. Women who live with the in-law family are at least $24.6 \%$ more likely to experience emotional abuse committed by their husbands/partners. A similar effect does not emerge between physical violence, either severe or less severe, and a presence of the Queen Bee in the household.
\end{abstract}

JEL Classification: Z13; J12; J16

Keywords: Domestic Violence; Queen Bee; Social Norms; Tradition; Patrilocal Marriage; Tajikistan.

Acknowledgements: We are grateful to Stephanie Karol, Joshua Jacobs, and Susan Steiner for comments on an earlier draft. They bear no culpability for errors, misinterpretations, or other shortcomings in this paper. 


\section{INTRODUCTION}

Abuse by female perpetrators against female victims receives little attention in economics. Oppression of women by women in the workplace, dubbed the Queen Bee (Stanes et al., 1973), describes paradoxical behavior of female executives, who, having achieved higher rank in the maledominated workplace, then oppose the ascent of other women up the career ladder. Male executives do not appear to demonstrate similar behavior against other males.

We argue that the Queen Bee $(\mathrm{QB})$ phenomenon can be instrumental in maintaining a society that oppresses women. Specifically, if QB behavior enhances social oppression, we would expect to find particularly adverse conditions for younger women who find themselves at the mercy of a QB. Such an effect does indeed emerge: using data for Tajikistan, we find that younger women in this situation are more likely to experience emotional (though not physical) domestic violence.

QB behavior is observed across patriarchal societies of the developing world. A vast body of literature documents oppressive cultural practices around the world where elder women often play a leading role perpetuating oppression against women. Examples include bride kidnapping (Central Asia, Caucasus), "enslaving” daughters-in-law (much of Central and South Asia), genital mutilation in parts of Africa and the Middle East), and Shim-pua marriages (China and Taiwan) - a traditional marriage, where the future bride is adopted from young age and raised by the in-law family alongside the future groom.

A QB is involved in all facets of her daughter-in-law's life in Tajikistan, a former Soviet republic in Central Asia. From the time a bride crosses the threshold of her in-law's domicile, the mother-in-law becomes a central and often sole decision-maker in all of the bride's decisions, including childbearing, employment, education, family budget management, family and friend visitations, child-naming and even minutiae such as the choice the color of curtains. 
The extent and severity of a mother-in-law's involvement depends on a family's and the bride's socio-economic background, ages, and local cultural norms. However, even for the most autonomous daughter-in-law, explicit recognition of a mother-in-law's superior status, even if only symbolic, is warranted. In such a case, instead of asking for a permission to visit her parents, the daughter-in-law may seek advice on whether the timing is good, thus letting her mother-in-law know of her intentions.

The motivation to restrict a daughter-in-law's social life, external employment, education, or indeed any self-enrichment activities outside the house, is essentially pragmatic. Tajik society upholds strict gender roles assigning the place of women in the kitchen, in attendance to men, and in childrearing: household chores fall almost exclusively on women. The young and physically capable daughter-inlaw thus frees the elder, less physically able QB from performing work. However, as with any human activity practiced over time, the household "enslavement" of daughters-in-law has acquired a symbolic dimension: the daughter-in-law also has a lower status in the in-law family hierarchy. It is not unusual for the daughter-in-law to be in service of her sisters-in-law - other females in the household physically capable of performing household chores.

The centrality of a mother-in-law figure and her subjugation of the daughter-in-law constitute an accepted status quo in Tajik society. Indeed, it is so ingrained in all socio-economic classes that neither its fairness nor economic consequences receive attention, even though it means that those young women with higher education end up withdrawing from the workforce in their prime years or may never join the workforce, thereby effectively wasting human capital.

The issue is only occasionally brought up by mainstream media and discussed in social network sites. Asia Plus, a leading online newspaper, published an article in 2013 entitled Mother-in-law vs. Daughterin-law: Who heads the Tajik housebold? (http://news.tj/ru/news/svekrov-ili-nevestka-kto-v- 
tadzhikskom-dome-khozyain). It conveys the commonly held understanding among young women that "the first [main] husband in the family will be her mother-in-law." Difficult relations with the mother-in-law is often cited as the basis for dissolution of marriage, and mistreatment of the young women by their in-law family is often an alleged reason for suicide. (http://news.tj/ru/news/chtotolkaet-tadzhikskikh-zhenshchin-na-tragicheskie-postupki).

According to the Tajikistan 2012 Demographic and Health Survey (TjDHS 2012), nearly 1 in 50 women reported having experienced QB physical abuse, and this likely is a lower bound. Save for Turaeva (2015), who uses an overlapping generations' model to explain the persistence of Queen Bee behavior, we know of no formal model that explains the paradoxical behavior of females in power. The current study aims at filling the corresponding empirical void by exploring the Queen Bee effect in the lives of young women living in patrilocal marriage in Tajikistan.

Section II reviews the literature on domestic violence (DV) and household composition. It emerges that DV is at greatest risk in non-cooperative marriages in which spouses do not cooperate and a Nash equilibrium solution is achieved by maximizing individual utility of each spouse given the behavior and threat points of the other. Section III surveys the anthropological literature on Central Asian QB/daughter-in-law relations. Families in Central Asia are generally patrilocal, with longstanding traditions of a kelin (literally, "newcomer") moving in with the in-law family. Section IV discusses the TjDHS data; the following section describes approaches to dealing with missing data. Section VI presents a principal components analysis (PCA) aimed at reducing dimensionality of both the response and explanatory variables. Section VII presents the major results of the study achieved through propensity score matching (PSM). The motivation to use PSM is to balance characteristics in treatment and control groups in order to create a quasi-experimental environment to estimate the 
average effect of the treatment. While we are unable to find a suitable instrument for IV analysis, PSM does allow us to carefully match on observables. Section VIII concludes.

\section{Prior Literature}

Economic analysis of marriage dates to Becker (1974). This neoclassical approach focuses on families whose members are cooperative and allocate goods to maximize a common utility function. Subsequent bargaining models such as McElroy and Horney (1981) and Manser and Brown (1980) view decision-making of a married couple as a Nash solution to a two-person bargaining game. In this model, although joint utility function is maximized, the solution must provide each spouse equal or greater utility than that obtained from outside marriage options. This constraint constitutes the individual's threat point (Manser and Brown 1980).

Although not uncommon, families with non-cooperative spouses have received relatively little attention. Obviously, households with domestic violence (DV) involve non-cooperative spouses. Farmer and Tiefenthaler (1997) propose a non-cooperative model of the family and analyze the equilibrium solution to a game in which each spouse with independent preferences maximizes utility given the behavior and threat points of the other. The man maximizes his utility by choosing the level of transfer to and the level of violence he inflicts upon his wife; the wife's threat point determines her utility from the transfer she receives from her husband along with the violence. As a woman's income (consumption) increases, her marginal utility of consumption decreases along with her tolerance of violence, thereby increasing her threat point. The inability to "buy" more violence on part of the husband leads to a decrease of violence. This conclusion seems intuitive: a woman's income is positively correlated with her ability to leave an abusive partner.

Empirical studies on DV have found strong correlation with economic hardship. DV rates also tend to fall as family financial status rises (Benson et al., 2003; Benson and Fox, 2004). For example, 
Lloyd (1997) presents the results of a random household survey that examines DV and women's labor force participation: women who reported having experienced abuse (physical, emotional or sexual) were more likely to have experienced unemployment, and also had lower personal income. Furthermore, Rensetti (2009) finds a reciprocal economic stress - DV relationship: while economic stress contributes to the likelihood of DV, DV may result in economic hardships for its victims through work absenteeism, lost opportunities and abusive partners deliberately sabotaging their spouse's employment.

Norms of male dominance also contribute to explaining higher DV in economically disadvantaged communities. When men fail in their traditional, breadwinner role they may assert their dominance through violence, including against the partner (Renzetti 2009). Analyzing data from National Survey of Households and Families, Benson and Fox (2004) find that families where husbands were consistently employed report a DV rate of $4.7 \%$. It increases to $7.5 \%$ and $12.3 \%$, respectively, in families where the male partner has experienced one or two or more periods of unemployment.

Violence perpetrated by females against other females is still a rarer subject of study, as a relatively low incidence of female-on-female violence reduces its importance to researchers and policy makers alike. Oppression of women by women in the workplace, though, is a well-recognized "Queen Bee" syndrome (Stanes et al., 1973), as male executives do not demonstrate similarly oppressive attitudes against their male subordinates. In the analysis below, we explore intra-household QB behavior.

While economic studies of QB behavior in Central Asian households are non-existent, a growing body of research studying the implications of household composition in different outcomes for married women living in the husband's natal home in South Asia provides valuable insights. Analyzing DHS data for 43 developing countries between 1990 and 1998, Bongaarts (2001) finds that Nepal and India have the highest average number of sons plus daughters-in-law living in the 
household across all countries in the study - an average of 0.3 and 0.29 per household, respectively. The average number for the Asian region, which also includes Kazakhstan, Uzbekistan, Kyrgyzstan, Indonesia, Pakistan, Philippines and Bangladesh, is 0.20 , substantially exceeding all other regions studied. Uzbekistan - Tajikistan's neighbor and fairly proximate in terms of culture and political history - has the third highest number in the sample, 0.28 sons plus daughters-in-law per household.

Using a large sample for India, Dimri (Dimri 2015) finds that presence of in-law parents is associated with disempowerment of daughters-in-law. She focuses on aspects of empowerment ranging from wearing a headscarf, needing permission to visit a local clinic, holding membership in a women's group; and household decision-making, including having decisions concerning childbearing, marriage of children, and purchase of items. Contradicting anecdotal evidence, Dimri implicates the father-in-law but not the mother-in-law in disempowerment of daughters-in-law.

In a study of six urban areas in northern Uttar Pradesh, women who live with their mothers-in-law or live in the husband's natal home (without the mother) are more likely to use modern family planning methods (Speizer et al., 2015). Ambiguous effects of mothers-in-law daughters-in-law health outcomes emerge in a qualitative study from Nepal (Simkhada et al., 2010). The study shows that mothers-in-law sometimes play a positive role in the uptake of antenatal care by their daughtersin-law, but more often the role is negative. In-depth interviews revealed that in many cases mothersin-law prioritize household chores over their daughters'-in-law antenatal care, expecting the latter to finish household work before they go for health visits, or not go at all. Cost considerations also appeared to play a key role.

Cultural norms also are significant determinant of wife abuse. Rao (1997) finds that in a potters' community in Southern India, reluctance of community members to interfere in incidents of wifebeating leads to legitimizing the ostensible reasons for a husband to beat his wife. Legitimate reasons 
include wife's sexual infidelity, negligence of household chores, disobedience, and dowry disputes. Similar results are found in a study of two low-income communities of Bangalore (Rocca et al., 2008). Defiance of social norms as demonstrated by the act of participating in social groups and vocational training before and after marriage, or entering a "love" marriage, are factors associated with a higher likelihood of becoming victim of DV (Rocca et al., 2008).

Increases in women's income, which may transgress social norms prescribing gender roles and power positions within a household, has an ambiguous DV effect in a village community in southern India. Unlike Farmer and Tiefenthaler (1997), who find that increased woman's income results in lower levels of domestic violence when divorce is stigmatized and not a desirable option, Srinavasan and Bedi (2007) argue that an increase in woman's income may lead to increase in the level of control-induced domestic violence. Moreover, they find an strongly positive correlation between wife's education and probability of DV, as an educated woman is perceived as posing a threat to man's authority.

Living with in-laws, as opposed to a nuclear family, also is associated with higher DV likelihood in two low-income communities in Bangalore (Rocca et al., 2008). Their qualitative data further suggest that mothers-in-law are sometimes the instigators of and accomplices in abuse of their daughters-inlaw. Similarly, Srinivasan and Bedi (2007) report that one-third of respondents mentioned parentsin-law and other in-law family members as assailants in abuse inflicted upon them.

Similar observations are achieved in a sociological study involving a sample of 100 inmates (50 males and 50 females) of the Central Jail, Jaipur, Rajasthan, incarcerated for committing familial murders (Jain 1992). More than half of the respondents reported committing violence as a result of trouble with the husband's parents: a wife is often falsely implicated by her in-laws or the husband by his own parents (Jain 1992, 52). 
Connors (1989) argues that oppression and violence against women serves to maintain the traditionally unequal family power structure. The structure is enhanced by empowering older women with the authority to dominate junior women, leading to the possibility of mothers-in-law being direct or indirect instigators of violence against daughters-in-law.

That it should exist in formerly Soviet Central Asia is even less surprising, since these societies combine male dominance in a patrilocal society with a degree of female autonomy introduced by the Soviets, and also with traditional deference to elders. The patriarchal and patrilocal structure reduces the status of young women; limited autonomy invites conflict, and the authority of elders - which transcends gender in many cases - leads to the concentration of family authority in the most active elder, who is likely to be female. The result is a Queen syndrome (Stanes et al., 1973), with the peculiar feature that women who are or were themselves victims of oppression can also be perpetrators of oppression against other women.

To our knowledge, only Turaeva (2015) has developed a formal economic model to explain QB behavior, though to some degree it can be viewed as being analogous to a prolonged apprenticeship or gradual accumulation of skill and status in a military organization setting. Turaeva (2015) uses an overlapping generations' (OLG) model to explain self-perpetuating QB behavior. She argues that by the time a woman ascends to QB status - becomes a mother-in-law - she has accumulated sufficiently large social capital to begin profiting from a system that endows her with authority over younger females. At this stage the mother-in-law engages in a norm-enforcing behavior which, among many things, means exploiting her daughter-in-law's labor in fulfilling household chores.

The empirical work below measures the effect of the presence of a Queen Bee on the incidence of DV in patrilocal marriages in Tajikistan. If a positive relationship exists, it implies that the QB structure is coercive rather than benign. Such coercive behavior is also implied by Turaeva's model, 
since it posits that an older generation of women will extract surpluses from younger women for the benefit of the general household, and that a younger woman's contribution will exceed the amount she would voluntarily contribute given autonomous agency.

By longstanding tradition, families in Tajikistan are preferably patrilocal, wherein newlywed couples move in with the husband's family, either in case of the youngest or the oldest son. Such a living arrangement may last for limited time or indefinitely, depending on the birth order of the husband. Generally, the oldest son of the family remains living in the parental house, although it is not unusual for the youngest son to do so. Strong anthropological evidence suggests that the husband's mother is endowed with ultimate power to control her daughter-in-law who is expected to be obedient.

\section{ANTHROPOLOGICAL EVIDENCE: TAJIKISTAN}

Marriage customs in Central Asia are well documented by anthropologists and ethnographers and are common theme of films and media. In Setdar Karadjaev's film A Quiet Bride, a young Turkmen city girl comes to the village to marry her fiancé. The young man offers his bride to go back to the city to avoid performing the wedding ceremony according to strict Turkmen traditions but his fiancée is excited to stay and participate in traditional rituals. Besides, she wants her future motherin-law to like her. The movie filled with light humor depicts the relations between the mother-in-law and the bride through droll situations making fun of the long-standing traditions in a gentle way. The young bride accepts and fulfills all the requirements of the mother-law such as being absolutely obedient to the mother-in-law, doing all chores around the house, attending to her husband, and following such traditions as speaking to the "grown-ups" only through her husband's younger sibling and covering her face when speaking to other males. The young woman follows all these requirements but cannot give up her profession and goes to work at the local hospital despite the 
mother's opposition. Her respectful persistence and good character soon melts the old woman's heart who finally accepts of her modern-minded daughter-in-law's ways. This movie appealed to Central Asian audiences, as people could draw many parallels between depicted traditions and their own family relations. In real life, though, such situations rarely evoke warm feelings and even more rarely have a happy ending.

Families in Central Asia are generally patrilocal, especially among the historically sedentary populations of Central Asia (Tajiks and Uzbeks). Anthropological records indicate the same tradition of a kelin (literally, newcomer) moving in with the in-law family in Uzbekistan (Akiner 1997b, 276). Harris $(2004,108)$ highlights the crucial role of the future mother-in-law in selection of the bride and also identifies the mother-in-law as the person who will have most contact with the kelin when the kelin lives with the family; and the harsh treatment of kelins. Researchers also emphasize the fairly nominal power of the patriarch, the male head of the family (Louw 2007, 76) and Harris $(2004,35)$, compared to the power that their spouses exert. Harris observes Tajik families where male heads "have relatively few functions in relation to their families", while women are responsible for "the running of the home and social reproduction of its members". However, few studies explicitly link domestic abuse of kelins to the presence of the mother-in-law, as in many cases they are the instigators of the abuse, rather than direct perpetrators. Roy $(2000,183)$ mentions an occasion when Islam Karimov, the late president of Uzbekistan, has "established a presidential contest for the best daughter-in-law, whose most valued quality is of course to obey her mother-in-law". Lack of obedience is often cited as key cause of DV in Tajikistan, as "nobody beats a good, obedient wife" (Sharipova 2008, 92).

Although we may establish a statistical evidence of the positive correlation between the incidents of domestic violence among women who live with their in-law families, it is difficult to determine a 
clear causal relationship. Hence, we cannot blame mothers-in-law unambiguously, as unobserved but relevant factors correlated with mother-in-law presence may cause omitted variables' bias. For example, we do not account for the presence of the father-in-law, who in principle could be an equal accomplice in the mistreatment of the daughter-in-law. There are two reasons for this omission. First, there is ubiquitous anthropological evidence stating the centrality of the mother-in-law figure, and not the father-in-law, in patrilocal families. Second, the data do not allow us to isolate the effect of the presence of the father-in-law. As is discussed below, household head gender is not a reliable instrument for isolating the effect. Consequently, the "Queen Bee effect" in this paper actually refers to a general type of family structure and precise responsibility cannot be assigned.

\section{DATA AND METHODOLOGY}

The Tajikistan Demographic and Health Survey (TjDHS) includes data on 6,432 households with a total 38,805 observations, including 9,656 women aged 15-49, and is representative for each of the nation's four provinces - Sughd, Khatlon, Gorno-Badakhshan Autonomous Oblast (GBAO), the so-called Districts of Republication Subordination (DRS) - and Dushanbe, the capital city. Sample households were selected in two stages. First, 356 clusters were selected from a master sample designed from the 2010 Population Census; then, participating households were listed in each cluster and were further systematically selected to participate in the Survey.

The survey was conducted by the Statistical Agency and the Ministry of Health from July to September of 2012 with the support of USAID as part of the MEASURE DHS program. Along with data on domestic violence against women, the purpose of the survey was to collect data on maternity and child health, childhood mortality, and knowledge of and behavior toward tuberculosis, HIV, and other diseases. TjDHS was based on model questionnaires developed by MEASURE DHS and adapted to Tajikistan by experts from the Statistical Agency and the Ministry of Health. 
Fourteen teams each consisting of four female interviewers, a field editor, and team supervisors were formed to conduct the Survey after receiving three-week training in June of the same year.

\section{TjDHS 2012 Key Findings on Domestic Violence}

In Tajikistan, 19 percent of women reported experiencing physical violence at least once since age 15. The comparable figure for neighboring Kyrgyzstan, the only nearby country with comparable

data, is even higher at 23\%. 13 per cent experienced violence in the past 12 months. 27 percent of ever-married women who reported having ever experienced physical or sexual violence committed by their partner/spouse endured physical injuries. Overall, approximately one in five of ever-married women experienced physical, emotional, or sexual violence from a husband. In 76.3 percent of cases, ever-married respondents indicate their current husbands/partners as persons who committed the physical violence. Other perpetrators include father/stepfather (4.5\%); mother/stepmother (9.7\%); sibling (7.8\%); and mother-in-law (1.6\%).

\section{Problem of Underreporting}

Domestic violence is usually a sensitive topic. In Tajikistan's shame-honor culture, collecting reliable data on violence is challenging. Due to different understandings of what constitutes violence (which in popular understanding includes only physical demonstrations of abuse) as well as a stigma associated in identifying oneself as a DV victim (Sharipova 2008), we expect that the incidence of violence will be underreported.

To mitigate the effect of cultural differences on the understanding of what constitutes violence the questionnaire prepared with specific questions on incidents of violent acts, such as:

"Did your (last) (husband/partner) ever:

- Push you, shake you, or throw something at you? 
- Slap you?

- Twist your arm or pull your hair?

- Punch you with fist or something that could hurt you"

The examples of questions testing on the subject of emotional or sexual abuse included:

- Physically force you to have sexual intercourse with him when you did not want to?

- Say or do something to humiliate you in front of others? ${ }^{1}$

- Insult you or make you feel bad about yourself?

This paper focuses on responses to acts of physical and emotional abuse but excludes sexual abuse. This is a hypersensitive subject in Tajikistan; we expect responses sexual abuse questions to be unreliable, with non-reporting unlikely to be random. About $99 \%$ of respondents in TjDHS stated that they had never been sexually abused by their partner which strikes us as a suspiciously high rate. Even for acts other than sexual abuse, and even though the survey has generally mitigated the effect of the differing cultural understandings of what constitutes violence, we doubt that underreporting was fully eliminated. Rather, the highly descriptive nature of the questions may have deterred women from giving truthful answers, or might have led them to downplay the severity of the incidents. Women might be inclined to check the option "Slap you", instead of "Punch you with fist or something that could hurt you"2.

\section{Study design}

We can only establish a correlational relation between the presence of the mother-in-law and the level of DV experienced by younger married women. Verifying a causal relationship would

\footnotetext{
${ }^{1}$ Besides carefully phrasing questions to avoid cultural bias, DHS also attaches a time window to each question; i.e., "in the past 12 months". This may lead to shifting reference points, for example as to what a woman considers humiliating as her marriage progresses.

${ }^{2}$ To test for the effect of underreporting we conducted a frontier regression analysis (see Appendix VI).
} 
necessitate designing an experiment by assigning young married women to living with their in-laws which is both infeasible and unethical. The data do not provide an obvious instrumental variable that would enable us to infer causality. Indeed, as is discussed below, even matching on observable characteristics is not easy.

Of 9,656 women interviewed only 5,568 were randomly chosen to participate in the domestic violence module. We further filter out unmarried women and those whose native language is Russian. Including only women whose native language is not Russian is necessitated by cultural differences between Russian and non-Russian ethnicities in Tajikistan, which also include Kazakhs, Uzbeks and Kyrgyz. This particular relationship dynamics between the mothers-in-law and their daughters-in-law is observed among Central Asian ethnicities, while Russian culture does not generally endow mothers-in-law with as much power over the daughters-in-law ${ }^{3}$.

After trimming, the data contain 4,048 observations that we assign to one of two groups: the treated group where women live with the in-law family; i.e., their relationship to the head of the household is indicated as "daughter-in-law", and a control group including all other women. Stratification of the sample into these two groups is a straightforward procedure as the data include women's response in terms of their relations to the head of household. This variable is designated qbee. A dummy variable TREAT $=1$ indicates membership in the treatment group and TREAT $=0$ indicates the control group.

Women's characteristics differ strikingly across the two groups (Table 1). Some of these differences are to be expected: average current age of women in treatment group is 27.3 years, 9 years younger than in control group; women's number of children under 5 years old is about twice as high in the treatment group (1.64 vs. 0.87 ); household head is about 20 years older in the treatment group, and

\footnotetext{
${ }^{3}$ It would be interested to compare the treatment of Russian daughters-in-law in inter-ethnic marriages, but cases are few. Russian ethnicity accounts for less than 1 percent of the total population.
} 
women in treatment group live in households with about 3 more family members. Treatment group women are generally younger because if they are to live with in their husband's natal home, they move in with parents-in-law right after the marriage. Women who identify themselves as wives (53.6\% of respondents) are former daughters-in-law whose parents-in-law are deceased or who moved out of their husband's natal home when a younger male member in the household brings in a wife, so that the services of the older daughter-in-law are no longer needed and/or there are housing space constraints. This scenario is often the case when women are married to middle sons in the household. Age differentials also explain differences in other demographic characteristics. Age difference at the time of the marriage does not differ much, as expected.

Beyond demographics, interesting differences are found in attitudes toward domestic violence. Women are asked whether or not they consider DV justified under different circumstances, for example, if women neglect their children or household responsibilities, burn food, or go out without permission. On average, women in the in the treatment group tend to justify domestic violence more than their peers in the control group. For example, on the question of whether beating is justified if wife goes out without permission (beating just1), the mean indicator for women in the treatment group is 16.4 percentage points higher than for the control group.

\section{Missing Data}

To proceed with the analysis we must first ensure that the data are complete. Appendix I shows that a number of observations in both explanatory and response variables are missing. To treat the missing data properly, it is important to establish the mechanism of missingness. If we can infer that the data are missing at random (MAR), or completely at random (MCAR), as opposed to missing not at random (MNAR), then the nonresponse can be ignored. Simply eliminating randomly missing 
data can be problematic from the power perspective, as the sample size for the analysis is reduced, but simply deleting randomly missing data will not bias the results (Osborne, 2013).

Let $\theta$ be a true parameter of population and let $\hat{\theta}$ be the estimator of the parameter based on the sample data. Ideally, we want $\operatorname{Bias}_{\theta}=E_{\theta}(\hat{\theta})-\theta=0$.

$$
\min \operatorname{MSE}_{\theta}(\hat{\theta})=V_{\theta}(\hat{\theta})+\left(\operatorname{Bias}_{\theta}(\hat{\theta})\right)^{2}
$$

where MSE is the mean squared error, a measure of the distance between the estimator and the parameter, which we want to minimize. The minimum MSE conveys the efficiency of the estimator of the population parameter.

Determining the estimator's unbiasedness and efficiency poses new challenges if there are missing data. Traditionally, non-response in surveys is categorized as unit nonresponse or item nonresponse. The former occurs when the data collection fails due to a logistical reason; e.g., the respondent was not home, while the latter occurs when the survey participant leaves some questions unanswered. Unit nonresponse has traditionally been treated by reweighting and the item nonresponse by single imputation (Schafer and Graham, 2002).

In the following we define an indicator variable $M$ for missingness, setting it equal to 1 when the data are present, and 0 otherwise. The distribution of this variable is often referred to as the missingness mechanism and we refer to the probability distribution of $M$ as the distribution of missingness.

Rubin (1976) first developed a classification of the distribution of $M$ according to the nature of the relationship of missingness to the data. Following Schafer and Graham (2002), we express such 
relationship as $Y_{c o m}=\left(Y_{o b s}, Y_{m i s}\right)$, where the complete set of data can be represented as the combined set of all observed and missing data. Missing data are MAR if $P\left(M \mid Y_{\text {com }}\right)=P\left(M \mid Y_{\text {obs }}\right)$; i.e., the distribution of $\boldsymbol{M}$ does not depend on missing values, but only on observed values. A special case of MAR is MCAR, missing completely at random, when the following holds: $P\left(M \mid Y_{\text {com }}\right)=$ $P(M)$, which occurs when the distribution of $M$ does not depend on observed data either. When MAR is violated, we have a case of MNAR, or non-ignorable nonresponse.

\section{Missing Data in the Sample}

The largest number of missing data are observed among independent variables: mar_to_birth (8.28\%) and cur_age_child (10.7\%). Other covariates such as employed, owns_house, owns_land, native_language, beating_just (1 through 5), Contr_hus (1 - 5), bus_tot_school have missing values under 1\% of the total. Since simple case deletion of under $1 \%$ missing values will not affect the overall quality of the analysis, we simply delete observations with the missing values in these categories. After deleting the insignificant number of missing values in the aforementioned variables, only $8.27 \%$ and $10.67 \%$ of the values in mar_to_birth and cur_age_child, respectively, remain missing.

Having performed tests for randomness of missing values (see Appendix III), we establish that missing observations in both mar_to_birth and cur_age_cbild are MAR. Thus, following the discussion on methods of dealing with missing data (Appendix II), we choose to simply delete incomplete observations. After deleting all missing data, we have 3,534 observations remaining. 


\section{MODEL SPECIFICATION}

\section{Multidimensionality of Response Variables}

The response variable is measured along 13 dimensions. In order to deal with the problem of multidimensionality of the data, we employ principal component analysis (PCA) to identify patterns in order to reduce the dimension of the data while keeping information intact (Appendix IV). The objective is to derive a subspace of data with less than 13 dimensions that represent the data well. To do this, we need to compute eigenvectors (the "components"), which are associated with eigenvalues that represent the length and magnitude of the eigenvectors. Larger eigenvalues will contain more information about data distribution and those will be the candidates for forming the subspace.

The procedure for conducting PCA includes detecting the highest correlation between the covariables and then calculating eigenvalues based on the correlation matrix. Correlations among response variables range from as low as 0.1 , for example, between bumiliated and knife to as high as 0.9, for example, between humiliated and emot (see Table 2). Near perfect correlation in the latter example is almost trivial: the variable emot contains women's responses to the a question whether or not they have ever felt humiliated, insulted, or made feel bad in any other way. The differences between bumiliated - knife (0.1), bumiliated - insulted (0.5), and the bumiliated - pushed (0.3) correlations are worth exploring further. We anticipate that the underlying reason for markedly different correlations is the nature of domestic abuse. Although nonviolent abuse may be a harbinger of future violent abuse, substantial time lags may keep correlations low. It also may be the case that those who suffer from "serious" abuse do not regard lesser abuse as worth reporting.

Table 3 shows that the first three components have eigenvalues higher than 1 . The first component explains 38\% variation in data and the second accounts for $12.6 \%$ percent of variation. 
Cumulatively, the first three components explain 62.8\% variation in the data. We choose to keep components with eigenvalues above 1. To better interpret the principle components, we use STATA's orthogonal rotation VARIMAX command. VARIMAX enables minimization of the complexity of PCA interpretation by amplifying the larger components' loadings and diminishing the smaller loadings. Component loadings represent the correlation between the components and the original variables. After rotating components and dropping loadings with absolute values less than 0.3 , we can see which of the original variables load highly on the components.

It is apparent that component 1 (Table 4) represents the most severe forms of physical violence, which include the survey respondents reporting being kicked or dragged, strangled or burnt, or having ever experienced any severe form of violence. Recall that the response variable is a multinomial variable with the higher ordered responses being affirmative regarding the incidence of domestic violence. We name these components as PHYS_SEV, PHYS and EMOT, in the order they appear. Within these three components we choose the variables with largest loadings to represent proxies for response variables for incidents of domestic violence: $p h y s \_s e v$, phys and emot.

Notice that variables knife (ever been threatened with knife/gun or any other weapon by partner/spouse) and twisted (ever had arms twisted or hair pulled by husband/partner) are not correlated significantly with any of the principal components; i.e., the variables are not correlated with any of the forms of the violence in question. One way to interpret such a result is taking into account the specific context of the domestic violence, which involves male husband/partner inflicting harm on the female spouse, and the connotation of the acts of violence such as knife and twisted. Using a weapon in a confrontation is a means of equalizing one's power with or surpassing the power of a counterpart in a confrontation. For example, a weaker husband may resort to weapons to deal with a stronger wife. The act of twisting arms or pulling hair is often resorted to in 
a physical confrontation of individuals with comparable strength, with one attempting to subdue the other. Since such a scenario can play out in a unique circumstances (the husband feeling the need to resort to weapons also interacts with their availability, as citizens are not allowed to own guns in Tajikistan; and/or a certain physical preparedness of the wife and her audacity to confront the husband, as women are traditionally raised to be submissive), it is not surprising that these two variables are not highly correlated with any of the principal components. Rather, the components reflect the more traditional dominant husband/weaker wife scenario.

\section{Principal Component Analysis of Explanatory Variables}

Details are provided in Appendix V. The key findings (Table 5) of the PCA analysis are as follows. Component 1 encompasses variables indicating how controlling the husband is. Thus we name the component CONTRH. The group of variables termed contr_bus includes women's responses to the question whether or not their spouses exhibit jealousy, suspect women of being unfaithful, or limit the time and frequency of women's visits to their families and friends, where a higher order of responses is affirmative of the fact of being controlled by the husband. The variable with the largest loading in component 1 is contr_bus4, which represents husband's limiting respondent's visits to family. In alternate regressions we use both the principal components and the variables that provide the largest factor loadings.

Component number 2 includes variables related to women's justification of violence. For instance, the participants were asked whether or not they think that the beating is justified in cases of the wife's neglecting children or burning meals. This variable represents the respondent's acceptance of the violence that is influenced by overall cultural acceptance of violence against women. We name this component ACCEPT. Similar to the first component, higher order responses in this multinomial variable are affirmative; i.e., the respondents justify or do not condemn violence. We 
alternately use variable beating just2 as a term that stands for justification of beating when wife neglects children.

The third component includes such variables as cur_age, cur_age_children, num_cbil_5, where the last stands for the number of children in the household under age of 5, which is also negatively correlated with the other two variables. Older women in the sample tend to have older children and a fewer number of children under 5 years old. We designate this component TENURE as it stands for the duration of the marriage. The fourth component includes variables related to the number of family members, the number of females in the household eligible for the survey (15-49 years old), and the age of the head of household. We name the fourth component FAM_SIZE.

Component 5, FIN_IND, corresponds to financial independence of the women. Component 6 includes variables covering total years of schooling of both the respondent and spouse, as well the as the wealth index assigned to the household. These variables are positively correlated, leading to an intuitive interpretation: more affluent individuals tend to be more educated and choose a partner who is educated. Since this component reflects socio-economic class, we name it SEC.

Component 7, which we name PER_IND standing for personal independence of the woman, includes variables for respondent's history with termination of pregnancy. We believe the decision to terminate pregnancy reflects woman's personal independence and inclusion of this variable in our model is important as it serves as a proxy for a women's power, vis-à-vis her mother-in-law, to make her own fertility related decision. Mothers-in-law are found to play an important role in daughtersin-law's reproductive health outcomes in two separate studies in India and Nepal (Simkhada et al. (2010); Speizer et al. (2015)).

Component 8 includes variables corresponding to the age at the time of marriage and how soon a married woman bears her first child. Newlywed women are commonly pressured to bear children 
soon after marriage. It is expected that women living with their in-laws would be more exposed to and often would submit to such pressure. Positive correlation between the two variables means that women who marry at older ages tend to take longer before having their first child. While the reason could be medical (i.e., older women have a harder time getting pregnant), given that women in Tajikistan marry at young ages, delayed childbearing likely reflects some unwillingness to submit to pressure. We choose variable age_at_mar as an alternative to component 8, which we name SUBMIS, reflecting a woman's propensity for submissiveness.

Component 9 includes such variables as sex_hhr (gender of the head of the household) and age_hh. We include sex_hbr in the model to possibly isolate the effect of the presence of the father-in-law, as opposed to the mother-in-law, on the treated group. Including household head age in the determination of the treatment effect is motivated by understanding that the QB effect is stronger with the ascension of the wife to formal household head status. We name this component simply as PIL (for parent-in-law) and use the sex_hbr as an alternative to this component.

Component 10 includes such variables as sibling_vio and mother_step_vio (the respondent experienced violence from mother or step-mother). We believe it important to include these variables in the model in order to account for past experience with domestic abuse, the implication of which we discuss in greater detail below. We name this component PAST_VIO and use the variable sibling_vio as a proxy for the past experience of domestic abuse.

It is interesting to note that variable employed does not substantially contribute to any of the components; i.e., there is no strong multicollinearity of the variable with other explanatory variables in the set. To interpret such a result, recall that women's formal employment outside the realms of the household in Tajikistan remains culturally sensitive. Thus, factors that conventionally determine the employment status of an individual woman, such as education, social class, age, and number of 
children, are of limited importance in the Tajik context. It is often the case that women with university education become full-time homemakers after marriage. Moreover, regardless whether or not a household is in dire financial circumstances, women often are discouraged from seeking employment. Likewise, in upper class families, daughters-in-law do not have any more autonomy in deciding whether or not to pursue a career. Factors that conventionally contribute to a woman's employment status are likely to be more relevant for those women who hold a family status other than daughter-in-law.

\section{RESUlts}

We first test our hypothesis by running three separate multivariate probit regression analyses with dichotomous outcome variables - phys_sev, phys, emot - and find predicted probability of living in an abusive household for daughters-in-law while controlling for 11 explanatory variables chosen through PCA (Table 6). We then compare results with the OLS coefficients based on principal components (Table 7). F

The variable sibling_vio and its $\mathrm{PC}$ alternative $P A S T_{-} V I O$ that reflect whether or not the respondent has ever been hurt by sibling emerges as key variable for all three outcome categories. There is a positive and statistically significant correlation between the respondents' experience of abuse in their natal home and the probability of ending up in an abusive marriage. A controversial victim precipitation theory in criminology (Wolfgang 1957) suggesting that victims are often active participants in the crime committed against them, also has been used to suggest that wife abuse may be provoked by the behavior and personality of the victim herself (Connors 1989, 28). While we are unpersuaded by "victim-blaming" theories, there must be an unobserved trait common to victims of abuse in the natal family that increases their chances to experience abuse in marriage. Obviously, this trait could be external to the individual, including immediate locally accepted behaviors, or unusually 
poor choice by abusive families in arranging marriages for their daughters. It could be also partially internal: abuse before marriage may lower self-esteem, thereby making one more vulnerable to subsequent abuse. In short, there are many possible mechanisms that would lead to the observed correlation.

The variable term_preg and its PC alternative, PER_IND, indicating whether or not the respondent ever terminated pregnancy, also shows statistically significant positive correlation with the average marginal probability of experiencing abuse across all three categories of the outcome (Tables $6 \& 8$ ). While there is some risk of reverse causality; i.e., domestic violence increases the likelihood that a woman may seek abortion, we anticipate that that the term mainly reflects a woman's autonomy. We do not believe that women may choose pregnancy as a form of assurance against abuse. According to data, $18.9 \%$ of divorced, separated or widowed women stated that they experienced physical violence during pregnancy. Among women who have ever been pregnant, 5.1\% experienced physical abuse while pregnant. However, transgression of the norms that deny young women power over fertility-related decisions may well induce acts of aggression from her husband/partner; to repeat, no one beats an obedient wife (Sharipova 2008, 92).

Curiously, the husband's reported temperament does not exhibit any statistically significant role (Table 6, column 1), though his schooling attainment does matter. One additional year of schooling slightly reduces the predicted probability of emotionally abusing his wife by 0.6 percentage points (Table 7c.i) Negative but insignificant correlations are found with regard to severe and less severe physical violence (Table $6 \& 7 \mathrm{a}, \mathrm{b})$.

Having a job shows a statistically significant positive correlation with the probability of experiencing severe physical abuse from one's husband/partner (Table 6, column 1). Correlation with probability of less severe and emotional abuse is positive but statistically insignificant. On the other hand, 
owning land, which is a reflection of woman's financial independence, reduces the predicted probability of emotional violence by 1.5 percentage points, but is insignificantly related to physical forms of abuse. These opposing results for two variables reflecting women's economic empowerment likely reflect culturally-motivated interpretations of what constitutes a transgression of norms. It appears that holding a formal job outside the house, inevitably resulting in independent interaction with the outside world (communicating with other men or learning new ideas) and having less time for fulfilling household chores may cause frictions in the marriage.

The results obtained from using simple variable as an alternative to the principle components give generally consistent results with varying robustness. The most notable differences are observed in predictions of domestic violence in terms of variables TREAT, cur_age_child and its PC alternative, TENURE; contr_bus4 and its PC alternative CONTRH; and hus_tot_sch. and its PC alternative, SEC.

Turning to the key variable of interest, the coefficient for TREAT is positive and statistically significant in predicting the incidents of emot, while controlling for other daughter-in-law characteristics. However, the same coefficient does not exhibit statistically significant influence on predicting the level of the emotional violence measured in terms of the principal component, EMOT (Tables 6 \& 7).

The analysis shows that living in the husband's natal home (with parents-in-law present) increasing the predicted probability of emotional domestic abuse by 2.9 percentage points (Table 7c.i). Compared to the mean value of 0.118 for the treatment group (Table 1), this represents a $24.6 \%$ increase in the likelihood of emotional violence. Probability of emotional violence for a daughter-inlaw living with a female head of household is slightly higher, by 3 percentage points, which represents a $25.2 \%$ increase from the mean level. Living with in-laws shows a statistically significant 
decrease in the PC coefficient for severe physical violence, however, this result does not hold in quasi-experimental design (Table 8, column 1).

Being a daughter-in-law marginally increases the probability of emotional abuse committed by husband/partner. It has a statistically insignificant but positive correlation with less severe form of violence, but insignificant negative correlation with severe physical violence. Thus, we conclude that the initial regression analysis partially but hardly completely supports our initial proposition of an adverse Queen Bee effect in the lives of Tajik daughters-in-law in Tajikistan. However, it is possible that there are many uncontrolled confounding variables that lead to this finding in our observational

study. To achieve a more robust evidence as to the presence of a Queen Bee effect, we next employ PSM to create a quasi-experimental environment. As noted above, there is still likely to be unobserved heterogeneity in the data; worse, as we shall see, it is not possible to balance on all observables. Nonetheless, the matching effort does serve to reduce differences in observable characteristics between treated and untreated populations.

\section{QUEEN BEE EFFECT}

While every woman getting married faces the prospect of living with a Queen Bee at least for a period of time, we suspect there still exists a selection bias. Customarily, it is the first-born son who remains in the household with his spouse and children to take care of the aging parents and who also inherits the parents' assets. There is no reason to believe that the birth order of the man enters the women's consideration of a marriage prospect. First, living with in-laws is a widely accepted tradition and respect for a mother-in-law figure (and father-in-law, for that matter) is instilled in Tajik girls at young age. Second, it is not always the first-born son in the family who remains living with parents. The choice is often circumstantial. It is not unusual for the youngest son to carry the torch for the family. 
On the other hand, it is plausible that the selection of a new family member for an indefinite period does enter into the selection process of the daughter-in-law, where the mother of the prospective groom is the key player. The existence of brides with different culturally valued attributes and qualities, such as virginity, skills of housewifery, meek character, physical appearance, and family background imposes an important responsibility on future mothers-in-law, as the selection process and final outcome are rife with uncertainties. The interaction of quality differences and uncertainty necessitates and explains the presence of a strong female figure on the groom's side of the marriage market, and who serves as proxy for their sons.

In assessing the quality of the prospective daughter-in-law, a mother-in-law relies on observable characteristics of a given prospective bride: age (most important), years spent in school; in case of advanced degree: years remaining to graduate, prospective profession; if graduated, whether or not in the workforce; family income, and social status. The number of siblings is likely irrelevant, unless the number is large.

There exists information asymmetry about the quality of the future daughter-in-law. Parents know best whether or not they have brought up an obedient daughter, or an overall adept girl willing to live in patrilocal household composition, characteristics that the future mother-in-law and her son can never fully investigate. However, in the quasi-arranged marriage market setting of Tajikistan, girls living in traditional patrilocal families are those most likely to possess desirable traits. Such daughters-in-law are more likely to have gotten married at younger age (since the first-born son is more likely to be married at younger age), are more likely to have fewer years of schooling and therefore are less likely to hold an advanced degree; are less likely to hold a formal job; are more likely to bear children in the first year after the marriage and have a close interval between 
subsequent births, especially if the children already born are female. Further, these women are less likely to own any property and are more likely to be financially dependent.

Therefore, in order to correctly assess the Queen Bee effect we must employ a propensity matching technique to balance observable characteristics in treatment and control groups and estimate the effect of the treatment; i.e., the effect of living with a mother-in-law on the incidences of domestic violence. Balancing on observables is of course only a minimum step: unfortunately, unobservable traits may also matter, and we are unable to identify any plausible IVs.

To match treatment and control groups, let $y_{0}$ be a random variable that is the response variable in the absence of the treatment and $y_{1}$ be the outcome when $T R E A T=1$; i.e, when a woman indicates her relationship to the head of household as "daughter-in-law". Recall that after reducing the dimensionality of the response variables, three outcome variables are chosen - phys_sev, phys, emot. In the proceeding analysis we measure the Queen Bee effect in terms of each of the dimension of domestic violence. The goal is to estimate the average treatment effect of TREAT on the treated and the average treatment effect in the population.

The average treatment effect on the population is (Greene 2012, 934):

$$
A T E=E\left[y_{1}-y_{0}\right]
$$

$A T E$ denotes the effect of the treatment on the individual randomly selected from the entire population. A more desired estimate that suits our study better, since the assignment to the treatment group is not absolutely random, is $A T E T$, the average treatment effect on the treated, which is an estimation of the Queen Bee effect on in the lives of the daughters-in-law: 


$$
A T E T=E\left[y_{1}-y_{0} \mid T R E A T=1\right]
$$

If the treatment is completely random then

$$
\begin{gathered}
E\left[y_{j} \mid \text { TREAT }=1\right]=E\left[y_{j} \mid \text { TREAT }=0\right]=E\left[y_{j} \mid \text { TREAT }=j\right], \text { where } j=0,1 \\
A T E=E\left[y_{1} \mid T R E A T=1\right]-E\left[y_{0} \mid \text { TREAT }=0\right]
\end{gathered}
$$

The use of propensity matching technique to estimate the treatment effect is motivated by the fact that the treatment assignment is not absolutely random.

\section{Propensity Score Matching}

To establish a more robust causal relationship, as opposed to correlational relationship, between the presence of a Queen Bee and the level of domestic violence we employ a PSM technique. Matching involves selecting observations from the treated group to match those in the control group, where the distribution of observed covariates in the treatment group is as similar as possible to the distribution in the control group. PSM involves calculating the propensity score, which is the probability of being in the treatment group given the observations have same pre-treatment characteristics. Since assignment to the treatment group is not random, using PSM in essence creates a "quasi-randomized" experiment.

We match observations in the two groups by finding the propensity score using a parametric method - specifically logit regression - to estimate the probability of a person being in the treatment group while possessing certain pre-treatment characteristics. The logit model uses TREAT as 
dependent variable and all the characteristics of the observations as independent variables. Let $p(X)$ stand for propensity score, then:

$$
p(X)=\operatorname{prob}(T R E A T=1 \mid X)=E(T R E A T \mid x)
$$

The propensity score is the conditional expectation of being in the treatment group given the characteristics $X$. PSM then assigns weights to the control group to make variables in the control group as similar as possible to the treatment group. After matching, the outcomes can be compared using weighted differences in mean outcomes between treatment and control group to find effect.

\section{Effect of the Treatment}

Using STATA's teffects psmatch command, the treatment effect is estimated for each of the components of the domestic violence - phys_sev, phys and emot. Each individual in each group was matched along 11 explanatory variables - contr_bus4 beating_just2 cur_age_child num_women owns_land bus_tot_school term_preg age_at_mar sex_hhr sibling_vio employed. Detailed analysis appears in Appendix IX. Several major findings emerge.

Unmatched Characteristics: For each of domestic violence components, the balancing property was not satisfied along such characteristics as current age of children (cur_age_child), number of women in the household aged 15-49 (num_women), owning a land (owns_land), husband's total years of schooling (bus_tot_school), and the sex of the head of the household (sex_hbr). It is trivial that the two groups would not match on the cur_age_child and num_women, as they serve as proxies for years spent in marriage and the family size, respectively. Larger family sizes tend to include two to three generations of the family members; those daughters-in-laws who are old enough not to have their in-laws living would not indicate themselves as "daughter-in-law" but rather "wife" or "head of household" if widowed. On the other hand, those women who are daughters-in-law tend to have younger children. 
It is only slightly less surprising that the two groups would not match along the owns_land and bus_tot_school. We view the first variable as a proxy for financial independence and the second for socio-economic class (SEC): recall that hus_tot_school is highly correlated with a household's wealth index and respondent's total years of education. Women in the treatment group lack financial independence, where the latter is defined by the fact of holding property, compared to their peers who do not live with their in-law family.

The lack of common support in the two groups along the SEC characteristic can be explained by the fact that the choice of living with in-laws is not entirely a matter of unwavering adherence to coresidence social norms in traditional societies. Often, the decision to move in with the husband's natal household is guided by economic considerations. In general, household composition tends to fluctuate with economic conditions. A study of U.S. households census during the recent recession found that the number and percentage of adults living in shared households increased by 11.4 percent between 2007 and 2010 (Mykyta and Macartney 2012). While there is no available study in the context of Tajikistan, it is likely that a similar correlation holds.

The characteristic owns_land that serves as a proxy for financial independence is not shared by the two groups, reflecting once again the culturally restricted status of daughters-in-law in Tajik society. Parental property is customarily inherited by the oldest son of the family (or the one who remains living with the parents), although both Shari'a law and the constitution of Tajikistan prescribes inheritance rights to the daughters of the family. The lower status of the daughter-in-law in the hierarchy of the in-law family excludes her from possible ownership of any assets of the in-laws. Women may gain property ownership later in life, which by no accident will coincide with her ascension to the status of the Queen Bee. 
The lack of balancing along sex_hhr variable can be explained with less certitude, and only by alluding to cultural norms. It is customary for the elder male in the household (usually the father-inlaw) to assume the title of the head of the household, regardless whether or not he is the actual breadwinner. In the event of the elder male's death or permanent absence, the oldest son who remains living in the household may assume the designation of the head of the household, in which case in the survey question his wife would call herself as the "wife" of the head of the household. In general, cases when a woman would call herself the head of the household in the absence of her husband and adult married son are circumstantial. Thus, the fact that very few of the daughters-inlaw had a female head of household is due to customary response practices.

Re-specification of the Propensity Score: To satisfy the balancing property, the number of explanatory components was reduced to six through the process of step-by-step elimination. The remaining characteristics shared by both groups are: contr_bus4, beating_just2, term_preg, age_at_mar, sibling_vio, employed. By excluding variables that do not satisfy the balancing property, we reduce the dimension of the explanatory variables to only those that are shared by women in both groups. The resulting collection of matching characteristics is telling on its own and intuitive: the tradition of living with the mother-in-law is pervasive. It is present irrespective of individual's level of autonomy or attitude toward domestic violence, or the man's culturally-informed way of demonstrating masculinity. However, we emphasize that acceptance of the results below implies accepting that the terms that did not balance do not themselves affect the risk of domestic violence and are uncorrelated with unobserved factors that affect the risk of domestic violence.

Treatment Effects: After satisfying the balancing property the following treatment effects were found in terms of each of the dimensions of domestic violence (Table 9). In terms of both ATE and ATET, living with parents-in-law does not show any statistically significant effect on the likelihood 
of domestic abuse. In terms of emotional violence, however, the results indicate that daughters-inlaw are more likely to suffer from emotional abuse. Both ATET and ATE are statistically significant. ATET, the effect we are more interested about given the study design, shows 3.3 percentage point increase in the likelihood of emotional abuse. This represents a $14 \%$ increase from the earlier indicator and 28\% increase from the mean value of the level of emotional abuse for the treatment group.

\section{CONCLUSION}

There are limitations to the methods used in this study. While PSM is a reliable statistical tool in achieving more robust results where experimental design is not feasible, the matching can only be performed on observed characteristics, and unobserved heterogeneity is not addressed. However, the pervasiveness of the Queen Bee phenomenon across social classes in Tajikistan's fairly homogeneous society slightly reduces unobserved heterogeneity concerns.

The results of PSM analysis in Appendix IX confirm the ubiquitous anthropological and anecdotal evidence of the detrimental effect of the presence of the Queen Bee effect in the lives of young married women. Women living in their husband's natal home having parents-in-law present are nearly one-quarter more likely to experience emotional violence. However, we do not find a correlation between physical violence, either severe or less severe, and the presence of the Queen Bee in the household. Regardless of the inferior position of the daughter-in-law, conspicuous abuse of the daughter-in-law as expressed in the physical manifestation of the violence is still frowned upon especially by the older generation, although a small number of women $(1.6 \%$ of the entire sample) did indicate that their mothers-in-law had ever laid her hands on them. Emotional abuse, on the other hand, does not generate physical evidence and in many cultures, including Tajikistan, is not generally regarded as abuse; thus, the presence of in-law parents abets rather than prevents the 
intimate partner from committing it (and, notably, their presence does not reduce the risk of physical violence).

This study confirming the ubiquitous anthropological evidence of the detrimental effect of the patrilocal living arrangement in the lives of young married women in Tajikistan is an important step in turning attention of researchers and policy-makers alike to a group of seemingly unlikely perpetrators of discrimination against women - women themselves. The finding here is almost certainly a lower bound, since many in the control group women also will be afflicted by Queen Bees, but, since the daughter-in-law is married to the eldest male, will report herself as the head's wife. Thus, the "untreated" group actually will contain many who are in fact "treated," so that the effect picked up here is simply the difference in risk of treatment between the groups, which is a much smaller effect than if we were able to truly isolate the untreated. 


\section{REFERENCES}

Aigner, Dennis, C.A. Knox Lovell, and Peter Schmidt. "Formulation and Estimation of Stochastic Frontier Production Functions." Journal of Econometrics (North - Holland Publishing Company) 6 (1977): 21-37.

Akiner, S. "Between tradition and modernity: the dilemma facing contemporary Central Asian women." In Post-Soviet Women: From the Baltic to Central Asia, by M. Buckley. Cambridge: Cambridge University Press, 1997b.

Anthopolos, Rebecca, and Charles M Becker. "Global Infant Mortality: Correcting for Undercounting." World Development 38, no. 4 (2010): 467-481.

Benson, Michael L., and Greer L. Fox. "When violence hits home: How economics and neighborhood play a role." National Institute of Justice, September 2004: 1-12.

Beson, Michael L., Greer L. Fox, Alfred DeMaris, and Judy Van Wyk. "Neighborhood Disadvantage, Individual Economic Distress and Violence Against Women in Intimate Relationships." Journal of Quantitative Criminology 19, no. 3 (September 2003): 207-235.

Bongaarts, John. "Household size and composition in the developing world in the 1990s." Population Studies 55, no. 3 (2001): 263-279.

Breiding, M.J., J. Chen, and M.C. Black. Intimate Partner Violence in the United States - 2010. Atlanta: National Center for Injury Prevention and Control of the Centers for Desease Control and Prevention, 2014.

Connors, Jane Frances. Violence Against Women in the Family. New York: United Nations, 1989.

Dimri, Aditi. "Household composition \& women empowerment: Living with in-laws in India." Working Paper. February 2015.

Farmer, Amy, and Jill Tiefenthaler. "An economic analysis of domestic violence." Review of Social Economy, no. 55.3 (1997): 337+.

Greene, William L. Econometric Analysis. New York: Pearson, 2012.

Harris, Colette. Control and Subversion. Sterling, Virgina: Pluto Press, 2004.

Jain, Ranjana S. Family Violence in India. New Delhi: Radiant Publishers, 1992.

Kasimova, S. R. (Transformation of Gender Order in Tajik Society) Трансрормация гендерного порядка а Таджикском обществе. Dushanbe: Irfon, 2007.

Lloyd, Susan. "The Effects of Domestic Violence on Women's Employment." Law \& Policy 19, no. 2 (1997): 139-167.

Louw, Maria Elisabeth. Everyday Islam in Post_soviet Central Asia. New York: Routledge, 2007.

Manser, Marilyn, and Murray Brown. "Marriage and Household Decision - Making: A Bargaining Analysis." International Economic Review (Wiley for the Economics Department of the Unviersity 
of Pennsylvania and Institute of Social and Economic Research, Osaka University) 21, no. 1 (February 1980): 31-44.

McElroy, Marjorie B, and Mary Jean Horney. "Nash-Bargained Household Decisions: Toward a Generalization of the Theory of Demand." International Economic Review 22, no. 2 (1981): 333349.

Mykyta, Laryssa, and Suzanne Macartney. Sharing a Household: Household Composition and Economic Well-Being: 2007 - 2010. U.S. Census Bureau, 2012.

Osborne, Jason W. Best Practices in Data Cleaning. Los Angeles, London, New Dehli, Songapore, Washington DC: SAGE Publications, 2013.

Rao, Vijayendra. "Wife-beating in rural south India: a qualitative and economteric analysis." Social Science and Medicine 44, no. 8 (1997): 1169-1180.

Renzetti, Claire M. Economic Stress and Domestic Violence. National Online Resource Center on Violence Against Women , 2009.

Rocca, Corinne H, Sujit Rathod, Tina Falle, Rohini P. Pande, and Suneeta Krishnan. "Challenging assumptions about women's empowerment: social and economic resources and domestic violence among young married women in urban South India." International Journal of Epidemiology, 2008: 1-9.

Roy, Olivier. The New Central Asia: The Creation of Nations. New York: NYU Press, 2000.

Rubin, Donald B. Multiple Imputation for Nonresponse in Surveys. New York: JOHN WILEY \& SONS, 1987.

Schafer, Joseph L., and John W. Graham. "Missing data: our view of the state of the art." Psychological methods 7, no. 2 (2002): 147-177.

Schafer, Joseph L., and Nathaniel. Schenker. "Inference with imputed conditional means." Journal of the American Statistical Association 95 (June 1997): 144-154.

Sharipova, Muborak. "One More War Against Women: Historical and Socio-Cultural Apects of Violence Against Women in Tajikistan." In Gender Politics in Central Asia. Historical Perspectives and Current Living Conditions of Women, edited by Chirsta Hammerle, Nikola Langreiter, Margareth Lanzinger and Edith Saurer, 67 - 94. Bohlou, 2008.

Simkhada, Bibha, Maureen A. Porter, and Edwin R van Teijlingen. "The role of mothers-inlaw in antenatal care decision-making in Nepal: a qualitative study." BMC Pregnancy and Childbirth, 2010.

Simkhada, Bibha, Maureen A. Porter, and Edwin R. van Teijlingen. "The role of mothers-in-law in antenatal care decision-making in Nepal: qualitative study." BMC Pregnancy and Childbirth, 2010.

Speizer, llene S, Peter Lance, Ravi Verma, and Aimee Benson. "Descriptive study of the role of household type and household composition on women's on women's reproductive health outcomes in urban Uttar Pradesh, India." Reproductive Health, 2015. 
Speizer, Ilene S., Peter Lnace, Ravi Verma, and Aimee Benson. "Descriptive study of the role of household type and household composition on the women's reproductive health outcomes in urban Uttar Pradesh, India." Reproductive Health, 2015.

Srinivasan, Sharada, and Arjun S. Bedi. "Domestic Violence and Dowry: Evidence from a South Indian Village." World Development, 2007.

Srinivasan, Sharada, and Arjun S. Bedi. "Domestic Violence and Dowry: Evidence from a South Indian Village." World Development 35, no. 5 (2007): 857-880.

Staines, G., C. Tavris, and TE. Jayaratne. "The Queen Bee Syndrome." In The Female Experience, by C. Tavris. Del Mar, California: CRM Books, 1973.

Tajikistan Demographic and Health Survey. Statistical Agency under the President of the Republic of Tajikistan; Ministry of Health, Tajikistan; MEASURE DHS ICF International, Calverton, Maryland, USA, 2012.

Turaeva, Mavzuna. "Tenacity of Social Norms: How Economic Models Explain Perpetuation of Genderbased Discrimination." Durham: Unpublished, May 2, 2015.

Wolfgang, Martin F. "Victim Precipitated Criminal Homicide." Journal of Criminal Law and Criminology 48, no. 1 (1957). 
Table 1: Descriptive Statistics

Treatment Group

Control Group

\begin{tabular}{|c|c|c|c|c|c|c|c|c|c|c|}
\hline & & & & & & & & & & \\
\hline Variable & $\mathbf{N}$ & Mean & Std. Dev. & Min & Max & $\mathbf{N}$ & Mean & Std. Dev. & Min & Max \\
\hline emot & 1,204 & 0.12 & 0.32 & 0 & 1 & 2,330 & 0.08 & 0.28 & 0 & 1 \\
\hline phys & 1,204 & 0.18 & 0.38 & 0 & 1 & 2,330 & 0.17 & 0.38 & 0 & 1 \\
\hline phys_sev & 1,204 & 0.03 & 0.17 & 0 & 1 & 2,330 & 0.03 & 0.18 & 0 & 1 \\
\hline cur_age & 1,204 & 28.27 & 6.01 & 18 & 49 & 2,330 & 36.20 & 7.23 & 18 & 49 \\
\hline educ_years & 1,204 & 9.98 & 3.04 & 0 & 19 & 2,330 & 10.38 & 2.79 & 0 & 21 \\
\hline num_members & 1,204 & 8.36 & 3.15 & 3 & 24 & 2,330 & 5.67 & 2.04 & 1 & 19 \\
\hline num_women & 1,204 & 1.78 & 0.94 & 1 & 6 & 2,330 & 1.38 & 0.72 & 1 & 6 \\
\hline mar_to_birth & 1,204 & 30.56 & 112.88 & 0 & 996 & 2,330 & 36.31 & 123.61 & 0 & 996 \\
\hline age_at_mar & 1,204 & 19.95 & 2.93 & 13 & 33 & 2,330 & 20.08 & 3.32 & 10 & 47 \\
\hline employed & 1,204 & 0.21 & 0.41 & 0 & 1 & 2,330 & 0.29 & 0.45 & 0 & 1 \\
\hline owns_land & 1,204 & 0.81 & 1.21 & 0 & 3 & 2,330 & 0.96 & 1.18 & 0 & 3 \\
\hline term_preg & 1,204 & 0.22 & 0.41 & 0 & 1 & 2,330 & 0.32 & 0.47 & 0 & 1 \\
\hline num_child_5 & 1,204 & 62.84 & 10.18 & 29 & 95 & 2,330 & 0.92 & 0.98 & 0 & 6 \\
\hline age_hh & 1,204 & 0.84 & 1.52 & 0 & 8 & 2,330 & 41.52 & 9.34 & 17 & 89 \\
\hline beating_just2 & 1,204 & 0.22 & 1.03 & 0 & 8 & 2,330 & 0.75 & 1.47 & 0 & 8 \\
\hline contr_hus4 & 1,204 & 0.22 & 1.03 & 0 & 8 & 2,330 & 0.19 & 1.01 & 0 & 8 \\
\hline contr_hus5 & 1,204 & 0.58 & 1.11 & 0 & 8 & 2,330 & 0.50 & 1.06 & 0 & 8 \\
\hline hus_tot_school & 1,204 & 11.59 & 2.79 & 0 & 20 & 2,330 & 12.07 & 2.82 & 0 & 22 \\
\hline cur_age_child & 1,204 & 2.55 & 3.39 & 0 & 21 & 2,330 & 6.21 & 5.51 & 0 & 27 \\
\hline
\end{tabular}


Table 2: Correlational of Response Variables

\begin{tabular}{|c|c|c|c|c|c|c|c|c|c|c|c|c|c|}
\hline & humiliated & threatened & insulted & pushed & slapped & punched & kicked & strangled & knife & twisted & phys & emot & phys_sev \\
\hline humiliated & 1 & & & & & & & & & & & & \\
\hline threatened & 0.38 & 1 & & & & & & & & & & & \\
\hline insulted & 0.46 & 0.38 & 1 & & & & & & & & & & \\
\hline pushed & 0.28 & 0.25 & 0.22 & 1 & & & & & & & & & \\
\hline slapped & 0.27 & 0.21 & 0.18 & 0.52 & 1 & & & & & & & & \\
\hline punched & 0.24 & 0.29 & 0.29 & 0.34 & 0.35 & 1 & & & & & & & \\
\hline knife & 0.07 & 0.11 & 0.06 & 0.08 & 0.07 & 0.14 & 0.13 & 0.19 & 1 & & & & \\
\hline twisted & 0.24 & 0.27 & 0.26 & 0.41 & 0.34 & 0.51 & 0.42 & 0.27 & 0.14 & 1 & & & \\
\hline phys & 0.32 & 0.24 & 0.24 & 0.68 & 0.87 & 0.42 & 0.31 & 0.17 & 0.08 & 0.4 & 1 & & \\
\hline emot & 0.91 & 0.45 & 0.53 & 0.29 & 0.28 & 0.26 & 0.29 & 0.2 & 0.11 & 0.25 & 0.35 & 1 & \\
\hline phys_sev & 0.28 & 0.32 & 0.37 & 0.29 & 0.27 & 0.47 & 0.93 & 0.46 & 0.19 & 0.45 & 0.34 & 0.33 & 1 \\
\hline
\end{tabular}


Table 3: Principal Components Correlations of Response Variable

\begin{tabular}{lllll}
\hline Component & Eigenvalue & Difference & Proportion & Cumulative \\
\hline \hline Comp1 & 4.91 & 3.27 & 0.38 & 0.38 \\
Comp2 & 1.64 & 0.09 & 0.13 & 0.50 \\
Comp3 & 1.55 & 0.58 & 0.12 & 0.62 \\
Comp4 & 0.97 & 0.17 & 0.07 & 0.70 \\
Comp5 & 0.80 & 0.07 & 0.06 & 0.76 \\
Comp6 & 0.72 & 0.10 & 0.06 & 0.81 \\
Comp7 & 0.62 & 0.05 & 0.05 & 0.86 \\
Comp8 & 0.57 & 0.03 & 0.04 & 0.91 \\
Comp9 & 0.54 & 0.10 & 0.04 & 0.95 \\
Comp10 & 0.45 & 0.33 & 0.03 & 0.98 \\
Comp11 & 0.11 & 0.04 & 0.01 & 0.99 \\
Comp12 & 0.07 & 0.02 & 0.01 & 1.00 \\
Comp13 & 0.05 &. & 0.00 & 1.00 \\
\hline
\end{tabular}

$\mathrm{N}=3,534$

Table 4: Response Variable Principal Components, Rotated

\begin{tabular}{lcccr}
\hline Variable & C1 & C2 & C3 & Unexplained \\
\hline \hline humiliated & & & 0.60 & 0.15 \\
threatened & & 0.33 & 0.58 \\
insulted & & 0.39 & 0.47 \\
pushed & & 0.48 & & 0.37 \\
slapped & & 0.57 & & 0.20 \\
punched & 0.33 & & & 0.49 \\
kicked & 0.51 & & & 0.26 \\
strangled & 0.38 & & & 0.61 \\
knife & & & & 0.88 \\
twisted & & & 0.52 \\
phys & & & 0.10 \\
emot & & & 0.10 \\
phys_sev & & & 0.16 \\
\hline *Blanks are absolute loadings $<.3$ & & & \\
N = 3,534 & & &
\end{tabular}


Table 5: Explanatory Principal Components, Rotated

$*$ Blanks are absolute loadings $<.3$

\begin{tabular}{|c|c|c|c|c|c|c|c|c|c|c|c|}
\hline Variable & $\mathrm{C} 1$ & $\mathrm{C} 2$ & $\mathrm{C} 3$ & $\mathrm{C} 4$ & $\mathrm{C} 5$ & $\mathrm{C} 6$ & C7 & $\mathrm{C} 8$ & $\mathrm{C9}$ & $\mathrm{C} 10$ & Unexplained \\
\hline sex_hhr & & & & & & & & & 0.84 & & 0.20 \\
\hline sibling_vio & & & & & & & & & & 0.71 & 0.42 \\
\hline mother_step_vio & & & & & & & & & & 0.70 & 0.42 \\
\hline cur_age & & & 0.57 & & & & & & & & 0.21 \\
\hline num_members & & & & 0.61 & & & & & & & 0.13 \\
\hline num_women & & & & 0.63 & & & & & & & 0.25 \\
\hline mar_to_birth & & & & & & & & 0.58 & & & 0.54 \\
\hline age_at_mar & & & & & & & & 0.70 & & & 0.34 \\
\hline employed & & & & & & & & & & & 0.78 \\
\hline owns_house & & & & & 0.68 & & & & & & 0.24 \\
\hline owns_land & & & & & 0.68 & & & & & & 0.20 \\
\hline term_preg & & & & & & & 0.71 & & & & 0.22 \\
\hline educ_years & & & & & & 0.58 & & & & & 0.34 \\
\hline num_chil_5 & & & -0.44 & 0.31 & & & & & & & 0.25 \\
\hline age_hh & & & & 0.32 & & & & & 0.51 & & 0.40 \\
\hline wealth & & & & & & 0.45 & & & & & 0.45 \\
\hline beating_just1 & & 0.45 & & & & & & & & & 0.36 \\
\hline beating_just2 & & 0.47 & & & & & & & & & 0.31 \\
\hline beating_just3 & & 0.46 & & & & & & & & & 0.33 \\
\hline beat_just4 & & 0.42 & & & & & & & & & 0.45 \\
\hline beat_just5 & & 0.44 & & & & & & & & & 0.39 \\
\hline contr_hus & 0.33 & & & & & & & & & & 0.63 \\
\hline contr_hus2 & 0.44 & & & & & & & & & & 0.36 \\
\hline contr_hus3 & 0.46 & & & & & & & & & & 0.30 \\
\hline contr_hus4 & 0.50 & & & & & & & & & & 0.20 \\
\hline contr_hus5 & 0.48 & & & & & & & & & & 0.25 \\
\hline total_abort & & & & & & & 0.69 & & & & 0.23 \\
\hline hus_tot_school & & & & & & 0.63 & & & & & 0.37 \\
\hline cur_age_child & - & & 0.63 & & & & & & & & 0.16 \\
\hline
\end{tabular}


Table 6: Probit Regression Model

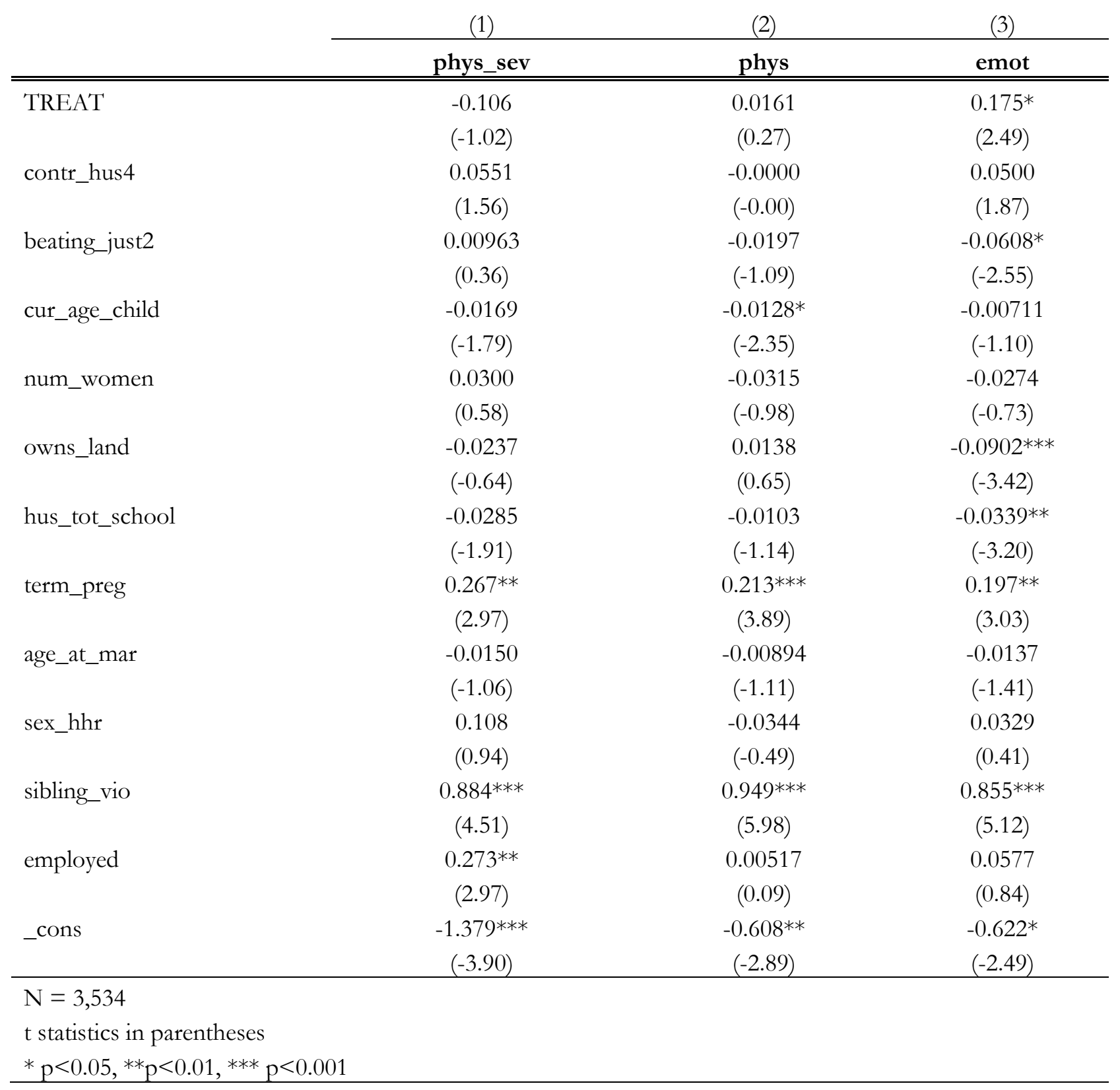


Table 7: Predicted Probabilities: Average Marginal Effects

Number of Observations $=3,534$

Model VCE : OIM

\section{a) Predicted Probability of Severe Physical Violence}

\begin{tabular}{lrrrrrr} 
& \multicolumn{7}{c}{ Delta-method } & & & \\
& $\mathbf{d y} / \mathbf{d x}$ & Std. Err. & $\mathbf{z}$ & $\mathbf{P}>\mathbf{z}$ & {$[\mathbf{9 5 \%}$ Conf. } & Interval] \\
\cline { 2 - 6 } TREAT & -0.009 & 0.009 & -0.970 & 0.334 & -0.026 & 0.009 \\
contr_hus4 & 0.004 & 0.003 & 1.500 & 0.134 & -0.001 & 0.010 \\
beating_just2 & 0.001 & 0.002 & 0.350 & 0.723 & -0.003 & 0.005 \\
cur_age_child & -0.001 & 0.001 & -1.670 & 0.095 & -0.003 & 0.000 \\
num_women & 0.002 & 0.004 & 0.570 & 0.568 & -0.006 & 0.011 \\
Owns_land & -0.002 & 0.003 & -0.640 & 0.520 & -0.008 & 0.004 \\
hus_tot_school & -0.002 & 0.001 & -1.830 & 0.068 & -0.005 & 0.000 \\
term_preg & 0.021 & 0.008 & 2.650 & 0.008 & 0.006 & 0.037 \\
age_at_mar & -0.001 & 0.001 & -1.040 & 0.296 & -0.003 & 0.001 \\
sex_hhr & 0.009 & 0.011 & 0.810 & 0.416 & -0.012 & 0.029 \\
sibling_vio & 0.071 & 0.019 & 3.640 & 0.000 & 0.033 & 0.109 \\
employed & 0.022 & 0.008 & 2.670 & 0.008 & 0.006 & 0.038 \\
\hline
\end{tabular}

\section{b) Predicted Probability of Physical Violence}

\begin{tabular}{lcccccc}
\cline { 2 - 6 } & \multicolumn{7}{c}{$\begin{array}{c}\text { Delta-method } \\
\text { dy/dx }\end{array}$} & Std. Err. & $\mathbf{z}$ & $\mathbf{P}>\mathbf{z}$ & [95\% Conf. & Interval] \\
\cline { 2 - 7 } TREAT & 0.004 & 0.015 & 0.270 & 0.789 & -0.026 & 0.034 \\
contr_hus4 & 0.000 & 0.007 & 0.000 & 0.998 & -0.013 & 0.013 \\
beating_just2 & -0.005 & 0.005 & -1.090 & 0.275 & -0.014 & 0.004 \\
cur_age_child & -0.003 & 0.001 & -2.360 & 0.018 & -0.006 & -0.001 \\
num_women & -0.008 & 0.008 & -0.980 & 0.326 & -0.024 & 0.008 \\
owns_land & 0.004 & 0.005 & 0.650 & 0.514 & -0.007 & 0.014 \\
hus_tot_school & -0.003 & 0.002 & -1.140 & 0.253 & -0.007 & 0.002 \\
term_preg & 0.054 & 0.014 & 3.900 & 0.000 & 0.027 & 0.081 \\
age_at_mar & -0.002 & 0.002 & -1.110 & 0.267 & -0.006 & 0.002 \\
sex_hhr & -0.009 & 0.018 & -0.490 & 0.627 & -0.044 & 0.026 \\
sibling_vio & 0.241 & 0.040 & 0.050 & 0.000 & 0.163 & 0.319 \\
employed & 0.001 & 0.015 & 0.090 & 0.929 & -0.027 & 0.030 \\
\hline
\end{tabular}




\section{c) i. Predicted Probability of Emotional Violence}

\begin{tabular}{lrrrrrr} 
& \multicolumn{7}{c}{ Delta-method } \\
& \multicolumn{1}{c}{$\mathbf{d y} / \mathbf{d x}$} & Std. Err. & \multicolumn{1}{c}{$\mathbf{z}$} & $\mathbf{P}>\mathbf{z}$ & $\mathbf{[ 9 5 \% \text { Conf. }}$ & Interval] \\
\cline { 2 - 6 } TREAT & 0.029 & 0.012 & 2.490 & 0.013 & 0.006 & 0.051 \\
contr_hus4 & 0.008 & 0.004 & 1.870 & 0.061 & 0.000 & 0.017 \\
beating_just2 & -0.010 & 0.004 & -2.540 & 0.011 & -0.018 & -0.002 \\
cur_age_child & -0.001 & 0.001 & -1.100 & 0.272 & -0.003 & 0.001 \\
num_women & -0.005 & 0.006 & -0.730 & 0.466 & -0.017 & 0.008 \\
Owns_land & -0.015 & 0.004 & -3.420 & 0.001 & -0.023 & -0.006 \\
hus_tot_school & -0.006 & 0.002 & -3.200 & 0.001 & -0.009 & -0.002 \\
term_preg & 0.032 & 0.011 & 3.020 & 0.002 & 0.011 & 0.053 \\
age_at_mar & -0.002 & 0.002 & -1.400 & 0.160 & -0.005 & 0.001 \\
sex_hhr & 0.005 & 0.013 & 0.410 & 0.683 & -0.021 & 0.031 \\
sibling_vio & 0.141 & 0.027 & 5.130 & 0.000 & 0.087 & 0.194 \\
employed & 0.009 & 0.011 & 0.840 & 0.399 & -0.013 & 0.032 \\
\hline
\end{tabular}

c) ii. Predicted Probability of Emotional Violence (with female head of household)

\begin{tabular}{lrrrrrr} 
& \multicolumn{7}{c}{$\begin{array}{c}\text { Delta-method } \\
\text { Std. Err. }\end{array}$} & $\mathbf{z}$ & $\mathbf{P}>\mathbf{z}$ & {$[\mathbf{9 5 \%}$ Conf. } & Interval] \\
\cline { 2 - 7 } TREAT & 0.030 & 0.012 & 2.580 & 0.010 & 0.007 & 0.052 \\
contr_hus4 & 0.009 & 0.005 & 1.840 & 0.065 & -0.001 & 0.018 \\
beating_just2 & -0.010 & 0.004 & -2.490 & 0.013 & -0.018 & -0.002 \\
cur_age_child & -0.001 & 0.001 & -1.090 & 0.278 & -0.003 & 0.001 \\
num_women & -0.005 & 0.006 & -0.730 & 0.465 & -0.017 & 0.008 \\
owns_land & -0.015 & 0.005 & -3.350 & 0.001 & -0.024 & -0.006 \\
hus_tot_school & -0.006 & 0.002 & -3.100 & 0.002 & -0.009 & -0.002 \\
term_preg & 0.033 & 0.011 & 2.940 & 0.003 & 0.011 & 0.056 \\
age_at_mar & -0.002 & 0.002 & -1.390 & 0.164 & -0.006 & 0.001 \\
sex_hhr & 0.006 & 0.014 & 0.400 & 0.693 & -0.022 & 0.033 \\
sibling_vio & 0.145 & 0.030 & 4.770 & 0.000 & 0.086 & 0.205 \\
employed & 0.010 & 0.012 & 0.840 & 0.399 & -0.013 & 0.033 \\
\hline
\end{tabular}


Table 8: OLS Model with Principal Components

\begin{tabular}{|c|c|c|c|}
\hline & $\begin{array}{c}\text { (1) } \\
\text { PHYS_SEV }\end{array}$ & $\begin{array}{c}\text { (1) } \\
\text { PHYS }\end{array}$ & $\begin{array}{c}\text { (1) } \\
\text { EMOT }\end{array}$ \\
\hline TREAT & $\begin{array}{l}-0.182 \\
(-1.96)\end{array}$ & $\begin{array}{c}0.0227 \\
(0.27)\end{array}$ & $\begin{array}{l}0.121 \\
(1.45)\end{array}$ \\
\hline CONTRH & $\begin{array}{c}0.0314 \\
(1.92)\end{array}$ & $\begin{array}{c}0.0124 \\
(0.83)\end{array}$ & $\begin{array}{c}0.0435^{* *} \\
(2.98)\end{array}$ \\
\hline ACCEPT & $\begin{array}{c}0.00371 \\
(0.22)\end{array}$ & $\begin{array}{l}-0.0224 \\
(-1.45)\end{array}$ & $\begin{array}{c}-0.0461 \text { ** } \\
(-3.07)\end{array}$ \\
\hline TENURE & $\begin{array}{c}0.000631 \\
(0.03)\end{array}$ & $\begin{array}{l}-0.0291 \\
(-1.39)\end{array}$ & $\begin{array}{c}0.00480 \\
(0.24)\end{array}$ \\
\hline FAM_SIZE & $\begin{array}{l}0.0256 \\
(1.06)\end{array}$ & $\begin{array}{c}-0.0141 \\
(-0.64)\end{array}$ & $\begin{array}{c}-0.0192 \\
(-0.89)\end{array}$ \\
\hline FIN_IND & $\begin{array}{l}-0.0387 \\
(-1.66)\end{array}$ & $\begin{array}{c}0.00862 \\
(0.40)\end{array}$ & $\begin{array}{c}-0.0454^{*} \\
(-2.18)\end{array}$ \\
\hline SEC & $\begin{array}{l}-0.0255 \\
(-1.07)\end{array}$ & $\begin{array}{c}-0.0388 \\
(-1.78)\end{array}$ & $\begin{array}{c}-0.00327 \\
(-0.15)\end{array}$ \\
\hline PER_IND & $\begin{array}{c}0.0517^{*} \\
(2.17)\end{array}$ & $\begin{array}{c}0.0986^{* * *} \\
(4.54)\end{array}$ & $\begin{array}{c}0.0417^{*} \\
(1.97)\end{array}$ \\
\hline SUBMIS & $\begin{array}{c}0.0190 \\
(0.73)\end{array}$ & $\begin{array}{c}-0.000509 \\
(-0.02)\end{array}$ & $\begin{array}{l}-0.0256 \\
(-1.10)\end{array}$ \\
\hline PIL & $\begin{array}{c}0.0449 \\
(1.35)\end{array}$ & $\begin{array}{c}-0.00972 \\
(-0.32)\end{array}$ & $\begin{array}{c}0.0343 \\
(1.15)\end{array}$ \\
\hline PAST_VIO & $\begin{array}{c}0.171^{* * *} \\
(6.24)\end{array}$ & $\begin{array}{c}0.184 * * * \\
(7.33)\end{array}$ & $\begin{array}{c}0.232 * * * \\
(9.46)\end{array}$ \\
\hline _cons & $\begin{array}{c}0.0618 \\
(1.44) \\
\end{array}$ & $\begin{array}{c}-0.00775 \\
(-0.20) \\
\end{array}$ & $\begin{array}{c}-0.0411 \\
(-1.07) \\
\end{array}$ \\
\hline $\begin{array}{l}\mathrm{N}=3,534 \\
\mathrm{t} \text { statistics in parentheses } \\
{ }^{*} \mathrm{p}<0.05, * * \mathrm{p}<0.01, * * * \mathrm{p}<0.001\end{array}$ & & & \\
\hline
\end{tabular}


Table 9: Average Treatment Effect after Propensity Score Matching

(1) (2) (3)

emot phys phys_sev

ATE

1.TREAT

\begin{tabular}{ccc} 
emot & phys & phys_sev \\
\hline \hline $0.0412^{* * *}$ & & \\
$(3.38)$ & -0.0006 & -0.0008 \\
& $(-0.04)$ & $(-0.11)$
\end{tabular}

ATET

1.TREAT

$0.0329^{* *}$

0.0043

$-0.0025$

(2.78)

$(0.30)$

$(-0.34)$

$\mathrm{t}$ statistics in parentheses

${ }^{*} \mathrm{p}<0.05,{ }^{* *} \mathrm{p}<0.01, * * * \mathrm{p}<0.001$

$\mathrm{N}=3,534$ 